\title{
ACAT as a Drug Target for Alzheimer's Disease
}

\author{
Henri J. Huttunen Dora M. Kovacs \\ Neurobiology of Disease Laboratory, Genetics and Aging Research Unit, MassGeneral Institute for \\ Neurodegenerative Disease (MIND), Massachusetts General Hospital, Harvard Medical School, \\ Charlestown, Mass., USA
}

\section{Key Words}

Alzheimer's disease - Amyloid · Cholesterol • Lipids •

Endoplasmic reticulum

\begin{abstract}
Accumulation of $\beta$-amyloid peptide $(A \beta)$ in the brain regions responsible for memory and cognitive functions is a neuropathological hallmark of Alzheimer's disease. Cholesterol may be involved in many aspects of $A \beta$ metabolism. It affects generation, aggregation and clearance of $A \beta$ in the brain. Not only the amount but also the distribution of cholesterol within cells appears to modulate $A \beta$ biogenesis. ACAT is an enzyme that regulates subcellular cholesterol distribution by converting membrane cholesterol to cholesteryl esters for storage and transport. We have used various cell- and animal based models to show that inhibition of ACAT strongly reduces $A \beta$ generation and protects from amyloid pathology. Here, we discuss data supporting ACAT inhibition as a strategy to treat Alzheimer's disease.
\end{abstract}

Copyright $\odot 2008$ S. Karger AG, Basel

The common pathogenic event that occurs in all forms of Alzheimer's disease (AD) is the abnormal accumulation of $\beta$-amyloid $(A \beta)$ peptide in amyloid deposits and cerebral blood vessels. Statins, a highly successful class of drugs that inhibit HMG-CoA reductase, have been shown to suppress $A \beta$ production in cell-based and animal models of AD. Retrospective clinical studies indicate that the prevalence and incidence of AD in subjects taking statins is remarkably decreased [1-3]. The limited number of prospective studies on statin therapy for AD have produced mixed results. Cholesterol-independent, indirect anti-inflammatory and antioxidant effects as well as inhibition of the isoprenoid pathway might be important for the efficacy of statins towards AD [4-8]. These ambiguous actions of statins on $A \beta$ production and other aspects of $\mathrm{AD}$ in vivo may partially explain the mixed clinical results and complicate the evaluation of the efficacy of statins for AD.

In addition to statins, other cholesterol-modifying strategies have been shown to attenuate $A \beta$ production. Acyl-coenzyme A:cholesterol acyltransferase (ACAT) is an endoplasmic reticulum (ER)-resident enzyme responsible for conversion of excess free cholesterol to cholesteryl esters [9-11]. Inhibition of ACAT function in cells either by genetic or pharmacological means has been shown to efficiently suppress $A \beta$ generation [12]. Metaanalysis of genetic data suggests that SOAT1 (the gene encoding ACAT1) is associated with the risk of AD [13] and that a common polymorphism that results in lowered ACAT activity might confer protection against AD [14]. The pharmaceutical industry has developed several ACAT

\section{KARGER \\ Fax +41613061234 \\ E-Mail karger@karger.ch}

www.karger.com (c) 2008 S. Karger AG, Basel

$1660-2854 / 08 / 0054-0212 \$ 24.50 / 0$

Accessible online at:

www.karger.com/ndd
Dr. Dora M. Kovacs

Neurobiology of Disease Laboratory, Genetics and Aging Research Unit

Massachusetts General Hospital, Harvard Medical School

114 16th St., Charlestown, MA 02129 (USA)

Tel. +1 617726 3668,Fax +1 617724 1823,E-Mail Dora_Kovacs@hms.harvard.edu 
inhibitors for treatment of hyperlipidemia and atherosclerosis that are safe for human use [15] and can be used to study the role of ACAT in AD. We have previously shown that a 2-month treatment with CP-113818 remarkably reduced amyloid pathology and correlated with improved spatial learning in transgenic mice expressing human $\mathrm{APP}_{751}$ containing the London (V717I) and Swedish (K670M/N671L) mutations (hAPP FAD mice) [16].

Avasimibe (CI-1011) is a widely studied ACAT inhibitor that is structurally unrelated to CP-113818. The pharmacological profile of avasimibe is somewhat different from $\mathrm{CP}-113818$. For example, $\mathrm{IC}_{50}$ values for avasimibe and $\mathrm{CP}$ 113818 are 391 and $6 \mathrm{nM}$ for HepG2 cells, and 664 and 63 nM for THP-1 cells, respectively [17]. Although $\mathrm{IC}_{50}$ values are lower for CP-113818, the ACAT1/ACAT2 selectivity is slightly better for avasimibe. As a proof-of-concept experiment, we have treated two age groups of female hAPP $\mathrm{FAD}$ and nontransgenic mice with two different doses of avasimibe. Avasimibe was administered in the form of implantable biopolymer pellets for 2 months. Although neuropathological and biochemical studies of brain amyloid plaque load are still ongoing, serum cholesterol levels suggested that avasimibe treatment was somewhat less effective in inhibiting ACAT as compared to CP-113818. This result was expected, considering the approximately 10 -fold higher $\mathrm{IC}_{50}$ value of avasimibe as compared to CP-113818.

As another proof-of-concept model for ACAT activity regulating $A \beta$ generation, we have used ACAT1 RNAi in human $\mathrm{H} 4$ neuroglioma cells. Reducing ACAT1 protein levels by approximately $50 \%$ resulted in significant decreases in APP-CTF levels in cell lysates as well as secreted $A \beta$ in the conditioned media [18]. Altogether, we have successfully used several independent pharmacological and genetic approaches to reduce ACAT activity in cell-based and animal models, all of which have proved to efficiently attenuate $A \beta$ generation and amyloid pathology.

A crucial difference between statins and ACAT inhibitors is the mechanism through which they attenuate $A \beta$ generation. Inhibition of HMG-CoA reductase by statins shuts down the L-mevalonate pathway affecting many cholesterol and isoprenoid-dependent processes in the cell. Cholesterol-rich membrane domains such as lipid rafts that are enriched in both $\beta$ - and $\gamma$-secretase activities are strongly affected by statin treatment. ACAT resides in the ER and its inhibition does not directly affect total cholesterol levels in the cell but regulates distribution of cholesterol between free and esterified pools. We have used 2-dimensional LC-MS to identify proteins that bind to APP differentially in ACAT inhibitor-treated cells. Several ER proteins, including chaperones of the GRP family, were identified as ACAT inhibitor-responsive APP-interacting proteins. In another line of study, we have identified HtrA2, a chaperone-protease, as an APP-interacting candidate protein that also seems to respond to ACAT inhibition. It appears that by affecting the intracellular distribution of cholesterol, ACAT inhibition indirectly modulates the fate of nascent APP molecules in the early secretory pathway.

In conclusion, several lines of evidence from cell-based and animal studies suggest that ACAT inhibition is an effective way of reducing cerebral $A \beta$ accumulation. The mode of action for ACAT inhibitors appears to be different from that of statins, suggesting that a combination of statins and ACAT inhibitors might offer additional therapeutic benefit. As avasimibe is an orally bioavailable ACAT inhibitor with a good safety profile and efficacy in humans, it will be essential to assess its clinical efficacy on cognitive impairment in AD.
References

ACAT as a Drug Target for Alzheimer's

Disease
1 Jick H, Zornberg GL, Jick SS, Seshadri S, Drachman DA: Statins and the risk of dementia. Lancet 2000;356:1627-1631.

-2 Wolozin B, Kellman W, Ruosseau P, Celesia GG, Siegel G: Decreased prevalence of Alzheimer disease associated with 3-hydroxy-3methyglutaryl coenzyme A reductase inhibitors. Arch Neurol 2000;57:1439-1443.

3 Huttunen HJ, Kovacs DM: Cholesterol and $\beta$-amyloid; in Sisodia SS, Tanzi RE (eds): Alzheimer's Disease. Advances in Genetics, Molecular and Cellular Biology. New York, Springer, 2007, pp 93-111.

4 Akiyama H, Barger S, Barnum S, Bradt B, Bauer J, et al: Inflammation and Alzheimer's disease. Neurobiol Aging 2000;21:383-421.
5 Kwak B, Mulhaupt F, Myit S, Mach F: Statins as a newly recognized type of immunomodulator. Nat Med 2000;6:1399-1402.

-6 Menge T, Hartung HP, Stuve O: Statins - A cure-all for the brain? Nat Rev Neurosci 2005;6:325-331.

7 Cordle A, Landreth G:3-Hydroxy-3-methylglutaryl-coenzyme A reductase inhibitors attenuate beta-amyloid-induced microglial inflammatory responses. J Neurosci 2005; 25:299-307.

8 Pedrini S, Carter TL, Prendergast G, Petanceska S, Ehrlich ME, Gandy S: Modulation of statin-activated shedding of Alzheimer APP ectodomain by ROCK. PLoS Med 2005;2: e18. 
$\checkmark 9$ Chang TY, Chang CC, Cheng D: Acyl-coenzyme A:cholesterol acyltransferase. Annu Rev Biochem 1997;66:613-638.

10 Buhman KF, Accad M, Farese RV: Mammalian acyl-CoA:cholesterol acyltransferases. Biochim Biophys Acta 2000;1529:142-154.

-11 Chang TY, Chang CC, Lin S, Yu C, Li BL, Miyazaki A: Roles of acyl-coenzyme A:cholesterol acyltransferase-1 and -2. Curr Opin Lipidol 2001;12:289-296.

-12 Puglielli L, Konopka G, Pack-Chung E, Ingano LA, Berezovska O, Hyman BT, Chang TY, Tanzi RE, Kovacs DM: Acyl-coenzyme A:cholesterol acyltransferase modulates the generation of the amyloid beta-peptide. Nat Cell Biol 2001;3:905-912.
13 Bertram L, McQueen MB, Mullin K, Blacker D, Tanzi RE: Systematic meta-analyses of Alzheimer disease genetic association studies: the AlzGene database. Nat Genet 2007; 39:17-23.

14 Wollmer MA, Streffer JR, Tsolaki M, Grimaldi LM, Lutjohann D, Thal D, Von Bergmann K, Nitsch RM, Hock C, Papassotiropoulos A: Genetic association of acyl-coenzyme A:cholesterol acyltransferase with cerebrospinal fluid cholesterol levels, brain amyloid load, and risk for Alzheimer's disease. Mol Psychiatry 2003;8:635-638.

15 Giovannoni MP, Piaz VD, Vergelli C, Barlocco D: Selective ACAT inhibitors as promising antihyperlipidemic, antiathero-sclerotic and anti-Alzheimer drugs. Mini Rev Med Chem 2003;3:576-584.
16 Hutter-Paier B, Huttunen HJ, Puglielli L, Eckman CB, Kim DY, Hofmeister A, Moir RD, Domnitz SB, Frosch MP, Windisch M, Kovacs DM: The ACAT inhibitor CP-113,818 markedly reduces amyloid pathology in a mouse model of Alzheimer's disease. Neuron 2004;44:227-238.

17 Alegret M, Llaverias G, Silvestre JS: Acyl coenzyme A:cholesterol acyltransferase inhibitors as hypolipidemic and antiatherosclerotic drugs. Methods Find Exp Clin Pharmacol 2004;26:563-586.

18 Huttunen HJ, Greco C, Kovacs DM: Knockdown of ACAT-1 reduces amyloidogenic processing of APP. FEBS Lett 2007;581: 1688-1692. 